\title{
La base demográfica de los sistemas socioculturales ${ }^{1}$ The demographic foundation of sociocultural systems
}

\author{
María Carmen Faus Pujol ${ }^{*}$ y Antonio Higueras Arnal $(\dagger)^{* *}$
}

Sin entrar en detalles conceptuales acerca de las grandes divisiones de la Geografía, aceptamos que la Geografía Social y Cultural forma parte de la Geografía Humana entendida como «estudio de las relaciones entre el hombre y el medio» según la define Demangeon (1942), y como «ciencia del hombre habitante» de Le Lannou (1949).

En el Dictionary of Human Geography, editado por Johnston, y otros en 1988, se define como objeto de la Geografía Social y Cultural «el estudio de los sistemas socioculturales», cuyo fundamento es la población organizada en sistemas demográficos.

Los sistemas demográficos se construyen a expensas de la población que en cada momento vive en las diferentes porciones de la superficie terrestre. La Humanidad está formada por el conjunto de personas que pueblan la tierra, en la actualidad supera los 7.058 millones (PRB, 2012), muy irregularmente repartidas sobre el planeta y con profundas diferencias fisiológicas y somáticas entre sus miembros. La Humanidad no es uniforme en absoluto, se percibe como un conjunto discontinuo formado por individuos singulares que conviven y se agrupan para satisfacer sus necesidades. En cierto modo la población

\footnotetext{
${ }^{1}$ El contenido de este artículo forma parte de la obra Fundamentos para una Geografía Social y Cultural iniciada con la colaboración del Profesor A. Higueras Arnal, actualmente en vías de finalización.

* Departamento de Geografía y Ordenación del Territorio, Universidad de Zaragoza (mc faus@unizar.es).

** Departamento de Geografía y Ordenación del Territorio, Universidad de Zaragoza (†).
} 
mundial puede concebirse como un conjunto de clusters en los que la colaboración de los individuos produce sinergias que multiplican la eficacia del sistema. Sin embargo, esa eficacia no es uniforme. El conjunto de la Humanidad se presenta diferenciado por el número de individuos que los integran, por las características de éstos y por la dinámica de los procesos de crecimiento interno. Además, a las diferencias de los propios agrupamientos humanos, hay que añadir la diversa naturaleza de los espacios que ocupan y de los modos de organizarse y colaborar para satisfacer aquellas necesidades.

Desde la antigüedad clásica se ha sostenido que «el hombre es la medida de todas las cosas» y que «el hombre es sociable por naturaleza». El «hombre habitante» definido por Le Lannou, tiene que satisfacer un cierto número de necesidades primarias y secundarias; y estas necesidades, aunque individuales, solo colectivamente pueden satisfacerse con eficacia. De ahí la exigencia existencial de que los hombres formen grupos y que se organicen colectivamente; es decir, que creen sociedades. Se han dado infinidad de definiciones de sociedad, pero todas ellas apuntan a que éstas están formadas por conjuntos de individuos y que se crean con algún propósito o finalidad. Según el papel que se les atribuya, las sociedades tendrán unas características u otras. En sentido estricto, el propósito de las sociedades humanas es siempre el mismo: satisfacer las necesidades. Eso explicaría el hecho de que las sociedades humanas tiendan a identificarse con sus propios modos de hacer las cosas, creando culturas originales que se nutren de creencias, técnicas, costumbres, actitudes, comportamientos, sentimientos, ideologías, mitos, símbolos, lenguajes, etc.

Se acepta que las sociedades humanas se formaron desde el primer momento de la aparición del hombre, aunque se ignora cómo funcionaban. A lo largo de los más de dos millones de años de edad que se atribuye a los restos humanos más antiguos conocidos, hasta llegar al hombre actual, se han sucedido muchas especies de homínidos, de cuyos modos de vida solamente tenemos vagos indicios proporcionados por los escasos restos de utensilios encontrados junto a sus fósiles. Algunos etólogos y antropólogos deducen el comportamiento social de aquellos antiquísimos antecesores del hombre actual, comparándolo con el de los primates actuales, a los que se atribuye parentesco filogenético con aquellos homínidos. Pero, por el momento, todo esto no son más que hipótesis y conjeturas, a la espera de confirmación científica. Cualesquiera que sean los orígenes de las sociedades humanas, es un hecho incontrovertible que la humanidad está fragmentada en grupos o sociedades de muy diversa naturaleza y con diferentes modos de actuar y de organizarse, según el sistema sociocultural adoptado, lo cual hace que los sistemas demográficos sean muy diferentes unos de otros. 
DeSIGUAL DISTRIBUCIÓN DE LA POBLACIÓN MUNDIAL. LAS DIFERENCIAS ÉTNICAS

Al estudiar la población mundial, lo primero que llama la atención es que se halla muy desigualmente repartida, como se aprecia en el mapa de D. Noin editado por la UNESCO en 1997. A juzgar por la dispersión de los hallazgos de restos fósiles de homínidos, el reparto de la población ha sido siempre muy irregular. En el siglo XIX, una vez terminada la era de los descubrimientos geográficos, se intentó buscar una explicación racional a dos hechos que hasta entonces habían sido considerados irrelevantes: la desigual distribución de la población en la superficie terrestre y las diferencias somáticas y culturales que se dan entre los diferentes grupos humanos.

En el mundo greco-romano, «ecúmene» era la tierra habitada, que coincidía con el mundo entonces conocido. Durante el siglo xIx, Ratzel, primero y Vidal de la Blache, después, extendieron la noción de ecúmene a toda la tierra, entendida como «morada del hombre», si bien la intensidad del poblamiento variaba de unos lugares a otros. Ante la desigual repartición de la población en la superficie de la tierra, algunos autores llegaron a plantear la cuestión del «óptimo de poblamiento» relacionándolo con la densidad de población, aunque, como puso de manifiesto Pierre George, a raíz de la Segunda Guerra Mundial, ambos conceptos son relativos.

El mapa de la distribución de la población mundial muestra cuatro áreas de gran concentración humana: el Sudeste Asiático, Europa Occidental, el este de los EE.UU y, en África, la cuenca subsahariana del Níger, más algunos islotes de poblamiento muy denso en las altiplanicies orientales del continente. Durante el siglo XIX se generalizó la idea de que la mayor o menor intensidad del poblamiento era consecuencia del clima. El «Determinismo Geográfico», que estuvo en boga hasta las primeras décadas del siglo xx, basado en las teorías de Darwin, Lamark y otros naturalistas, sobre la evolución y la adaptación de los seres vivos al medio, daba gran importancia al clima, como agente de la distribución de la población. De ahí se pasó a explicar el mayor o menor desarrollo de las sociedades y culturas humanas, según las condiciones de su propio medio natural y, más concretamente, del clima.

Todos los intentos de dar una explicación científica del desigual reparto de la población han fracasado. Lo único cierto es que hay infinidad de hipótesis más o menos plausibles, elaboradas desde multitud de puntos de vista, que intentan dar respuesta al hecho indiscutible del reparto desigual de la población mundial.

Aparentemente, y a juzgar por la distribución actual de la población, los espacios naturales más favorables para el hombre serían las zonas templadas y húmedas, situadas por debajo de los mil metros de altitud. Sin embargo, des- 
conocemos cuales eran las condiciones climáticas de esas zonas a comienzos del Holoceno, e incluso en tiempos mucho más recientes, y cual sería entonces su grado de poblamiento. En cualquier caso el hombre es un organismo animal vivo que en ausencia de acciones positivas de acondicionamiento del medio, necesita que el medio natural disponga de unas determinadas condiciones ecológicas para desarrollarse.

Desde un punto de vista estrictamente ecológico, los hábitats más apropiados para la vida, tanto de animales superiores, como de microorganismos, son los que gozan de temperaturas medias de $25-30^{\circ} \mathrm{C}$., sin grandes oscilaciones y amplitudes, y con un grado de humedad en torno al 50\%. Estas condiciones sólo se dan en los climas cálidos y húmedos, en los que, precisamente por ello, la biodiversidad, la variedad de ecótopos y nichos ecológicos y la concurrencia de organismos y microorganismos en aquellos medios naturales son altísimos.

Sin embargo, los climas cálidos y húmedos no son completamente favorables para el poblamiento humano. Salvo muy pocas excepciones, la mayoría de aquellos organismos y microorganismos, incluido el hombre, son antagónicos entre sí, y desarrollan una dura competencia por sobrevivir y ocupar los nichos ecológicos más favorables. Max Sorre en su obra Los fundamentos biológicos de la geografía humana. Ensayo de una ecología del hombre, (publicada inmediatamente después de la Segunda Guerra Mundial: 1947-1952), desarrolla el concepto de "complejo patógeno». Una de las causas del desigual reparto de la población mundial podría ser la mayor o menor eficacia de las poblaciones humanas para sobreponerse a los complejos patógenos a los que han debido hacer frente desde los albores de la humanidad.

Como hipótesis no demostrada, cabe admitir la explicación de Sorre acerca del desigual reparto de la población. Pero también hay que tener en cuenta la eficacia de las poblaciones humanas para sobreponerse al medio natural y satisfacer sus necesidades en competencia con otros seres vivos. Esta es, en síntesis, la idea de Vidal de la Blache sobre el género de vida. Esa eficacia es consecuencia del peculiar modo que el hombre, socialmente organizado, tiene de hacer las cosas, principalmente del modo de satisfacer sus necesidades primarias, empezando por la alimentación.

Las grandes transformaciones de la ecúmene se produjeron a partir del Holoceno, periodo geológico con el que, hace un millón de años, comenzó el Cuaternario que, al menos en Europa, se caracterizó por fuertes cambios climáticos y la alternancia de fríos glaciares e interglaciares templados. Durante este larguísimo periodo de tiempo, la eficacia de las diferentes culturas debió ser muy dispar, pero no hay evidencia de ello. Las primeras evidencias del cambio sociocultural datan de hace tan solo unos seis o siete mil años, coincidiendo con 
el Neolítico y la aparición de la agricultura, la ganadería, el sedentarismo y la construcción de las primeras ciudades. La primera revolución sociocultural y demográfica de la que tenemos noticias aconteció en el Neolítico, hace unos 10.000 años. De unos lugares a otros se aprecian desfases diacrónicos de hasta 3.000 años en la evolución sociocultural del Neolítico, que explicarían la irregular distribución de las grandes concentraciones de población.

Las mayores aportaciones culturales del Neolítico fueron la agricultura y la sedentarización. Las primeras poblaciones humanas, hace más de dos millones de años, surgieron con toda probabilidad en la actual franja intertropical que recorre África, Asia y el Pacífico. Pero las huellas de las culturas neolíticas más antiguas indican que estaban vinculadas a los cereales: el arroz en el Asia Monzónica; el trigo, en Mesopotamia y Egipto, y el maíz, en América. De ahí que algunos relacionen la distribución del poblamiento con las agriculturas cerealistas.

Ante la incertidumbre que provoca el no saber con certeza el origen de la desigual distribución de la población mundial, hay que insistir en el diacronismo de la evolución numérica de la humanidad y la existencia, cuando menos de dos modelos demográficos: el modelo histórico, que se remonta probablemente al Neolítico de cada área geográfica, y el que surge de la Revolución Demográfica en la Modernidad.

La existencia de diferencias somáticas entre los seres humanos es evidente. Estas diferencias se conocen desde antiguo, pero hasta tiempos relativamente recientes en que se difundió el concepto de «raza» no han sido objeto de valoraciones socioculturales. Aunque las razas son un hecho biológico, el estudio de las mismas no se suscitó en la biología, sino que nació en el seno de la teología y del derecho, como consecuencia de la profundización de la naturaleza del concepto judeocristiano de persona que es el fundamento de los avances que, desde el siglo XVIII, se han hecho en el reconocimiento de los derechos humanos.

La cuestión de la naturaleza del hombre y todo lo relacionado con sus derechos y libertades era objeto de discusión desde la época del Imperio Romano, pero adquirió nueva relevancia con el descubrimiento de América y el encuentro de culturas tan diferentes como las europeas y amerindias. El intento de convertir a los indígenas al cristianismo, los abusos que se cometieron al expulsar a los indios de sus tierras, el sistema de encomiendas, etc. llevaron a algunos religiosos, principalmente de la Orden de Predicadores, a denunciar aquellos abusos ante la Corona y a justificar con argumentos teológicos y jurídicos los derechos de los indígenas, por su condición de personas, que era lo que se discutía. En el siglo XVI, los dominicos Antonio Montesinos, Bartolomé de las Casas y Francisco de Vitoria, entre otros muchos, fueron los paladines de esta defensa que, con el tiempo, cuajó en el llamado «Derecho de Gentes». 
El concepto de raza aplicado a las poblaciones humanas adquirió nueva relevancia en el siglo XIX, coincidiendo con la generalización de las aportaciones de Buffon y Linneo a la clasificación sistemática de animales y plantas, la divulgación de la teoría de la evolución de Darwin, la consolidación del régimen geopolítico de grandes potencias y la formación de los modernos imperios coloniales. La Antropogeografía de Ratzel (1882-1891), que tenía formación de biólogo, fue, probablemente, la obra que más influyó en la valoración de las razas humanas, al relacionarlas con la cultura.

Las revoluciones demográfica y agraria del siglo XviII plantearon crudamente la cuestión de las razas humanas. En una época en la que nada se sabía de genética, las diferencias somáticas eran fundamentales para la clasificación de plantas y animales. La observación de que los animales modificaban ciertos caracteres de su aspecto para adaptarse al medio fue lo que permitió la elaboración de la teoría de la evolución, que pronto se aplicó también a las ciencias sociales. El Darwinismo Social sostenía que las razas son un producto de la naturaleza y, por lo tanto, cualquier intento de mejorarlas carecería de sentido. Otras teorías, que luego fueron aprovechadas por el nazismo alemán, sostenían la existencia de razas inferiores y superiores y, entre estas, la primacía de la raza aria.

Aparte del uso político que se hizo de estas teorías. Nada más comenzar el siglo xx los científicos demostraron lo inconsistente de las teorías barajadas hasta entonces para clasificar a los seres humanos por sus caracteres somáticos. En 1901, el médico austriaco Karl Landsteiner, descubre los «grupos sanguíneos» y en 1941, el mismo científico y sus colaboradores encuentran el «factor Rh» que determina algunas propiedades de la sangre. Estos descubrimientos, unidos a los progresos de la genética, dan un giro completo a las investigaciones sobre las diferencias somáticas de los seres humanos. Sin embargo, en los EE.UU la segregación racial perduró hasta la promulgación de la Civil Rights Act de 1964, y en Sudáfrica el sistema social del Apartheid no fue abolido hasta finales de la década de los años noventa del siglo xx.

Antropológicamente, las discusiones raciales quedaron definitivamente zanjadas en el Congreso Universal de las Razas celebrado en Londres en 1911. Los países allí reunidos llegaron a la conclusión de que «un investigador imparcial debería inclinarse por ver la importante variedad de pueblos del mundo, como seres esencialmente iguales en intelecto, capacidad de acción, moralidad y condiciones físicas». Finalmente, las Naciones Unidas y la UNESCO, han hecho multitud de declaraciones afirmando la unidad del género humano, proponiendo que en lugar de razas, se hable de "grupos étnicos», para poner de manifiesto que las diferencias no son biológicas, sino fundamentalmente culturales. 
El CRECIMIENTO DE LA POBLACiÓN MUNDIAL. LA TRANSICIÓN DEMOGRÁFICA. CAMBio DE MODELO DEMOGRÁFICO Y EVOLUCIÓN SOCIOCULTURAL

A escala planetaria el crecimiento de la población es únicamente vegetativo; es decir, por la diferencia entre nacimientos y defunciones. Todo indica que históricamente esta diferencia ha sido muy escasa hasta tiempos relativamente recientes. El ritmo de crecimiento de la población humana ha sido, pues, muy lento. La humanidad tardó probablemente más de dos millones de años en alcanzar la cifra de mil millones de seres, pero sólo ha tardado doscientos cincuenta años en sobrepasar los siete mil millones. Este crecimiento exponencial es lo que ha causado preocupación y perplejidad a los demógrafos, economistas y sociólogos, que han aventurado hipótesis y teorías acerca de las causas de este ritmo de crecimiento, su sostenibilidad y las consecuencias del mismo.

Desde la Biología se han realizado estudios para determinar el ritmo de crecimiento natural de las diferentes especies animales, entre ellas la humana. Por razones estrictamente biológicas, la natalidad natural no puede crecer indefinidamente, ni la mortalidad reducirse a cero. Los biólogos calculan que, dada la naturaleza de los seres humanos, la distribución estructural de la mortalidad, sus características fisiológicas, su sociabilidad y capacidad de innovación, la «natalidad máxima» de la especie humana, viviendo en sociedad, estaría entre el 55 y 60\%o. Algunos demógrafos han fijado en 35 \% la máxima natalidad humana, deducida del comportamiento, respecto de la reproducción de los Huteritas, una rama del Luteranismo fundada en el siglo XvI, cuyos miembros no practican ningún control de la natalidad.

Las cifras anteriores son poco fiables. De hecho, actualmente ningún país del mundo alcanza esas tasas, y no parece probable que las hayan alcanzado en el pasado, salvo durante periodos muy cortos y en situaciones excepcionales. También es muy incierta la situación de normalidad que se atribuye a los grupos humanos para calcular su crecimiento, pues nadie sabe en qué ha consistido históricamente la normalidad de los grupos humanos en lucha constante por la supervivencia. Todas las teorías sobre la población despliegan sus argumentos en torno a las causas que incrementan o reducen la natalidad y la mortalidad, las cuales se ven siempre afectadas por las condiciones socioculturales de los grupos humanos. Por razones socioculturales, la natalidad puede reducirse voluntariamente tanto como se quiera y la mortalidad incrementarse hasta el aniquilamiento.

La supervivencia del hombre sobre la tierra no ha sido fácil. Independientemente de los episodios bélicos que han llevado a los hombres a enfrentarse unos con otros, no se puede olvidar la afirmación de Sorre de que las pobla- 
ciones humanas han conquistado la superficie terrestre en lucha constante con otras especies animales y defendiéndose de los complejos patógenos propios de cada ambiente natural. La mortalidad general y sobre todo la mortalidad infantil han sido muy altas a lo largo de la Historia. Los estudios antropológicos de fósiles humanos pertenecientes al Paleolítico indican que en aquella época eran muy pocos los individuos de más de cuarenta años. Henri V. Vallois (1952), antropólogo y paleontólogo francés, estudió una muestra de 187 hombres prehistóricos que vivieron en el Paleolítico y el Mesolítico. De 20 individuos neandertales, solamente 1 había superado la edad de 40 años, sin sobrepasar los 60; de 102 individuos del Paleolítico Superior, 12 habían sobrepasado aquella edad; y de 65 del Mesolítico, solamente lo habían hecho 2. La Biblia cita personajes que vivieron centenares de años, pero la conclusión a la que llegan estudios como el citado es que la esperanza de vida era muy pequeña y se ha mantenido con muy pocas variaciones hasta nuestros días.

Como se ha dicho anteriormente, todas las estimaciones que se barajan indican que el poblamiento humano de la tierra tiene una antigüedad de más de dos millones de años pero el volumen total de la población y su repartición espacial en aquellas remotísimas épocas son completamente desconocidos. Las cifras son muy dispares, pues van desde los 10.000.000 de habitantes de los cálculos más optimistas, hasta la modesta cifra de 10.000 personas propuesta por los más críticos. Es una diferencia demasiado grande para que ambas cifras sean fiables.

Las cifras parece que empiezan a cuadrar en algún momento del Holoceno, en el paso del Paleolítico al Neolítico, hace unos 10.000 años. La irrupción del Neolítico originó la primera Revolución Demográfica de la que se tiene noticia. Aunque los cálculos son muy dispares, la población mundial a mediados del Neolítico, con las reservas propias de la diacronía espacial que caracteriza a todos los fenómenos demográficos, pudo ascender a unos 300 millones de personas. Probablemente fue en esta época cuando se marcaron las profundas diferencias en la distribución del poblamiento y se inició la formación de las grandes densidades asiáticas, que son anteriores a la Revolución Demográfica del siglo xviII.

Conocemos las consecuencias que la Revolución Demográfica del siglo XVIII tuvo en el crecimiento y distribución de la población mundial, pero se sabe muy poco acerca de cómo se formaron las grandes densidades anteriores a aquella. Las teorías elaboradas para explicar el crecimiento de la población durante la transición no son extrapolables al pasado ni al presente. Lo único cierto es que desde el Neolítico el progreso sociocultural de la humanidad ha sido espectacular y ello ha tenido que influir de alguna manera en el crecimiento de la población. Cabe admitir la hipótesis de que las grandes concentraciones humanas, como las del Sudeste Asiático, por ejemplo, se deben a la 
existencia de culturas antiquísimas cuyo crecimiento natural sería muy bajo, pero se habría mantenido durante muchísimo tiempo. Tal vez el Neolítico del Asia Monzónica sea mucho más antiguo que el Neolítico Mediterráneo, que es el que se utiliza habitualmente para delimitar las eras históricas.

La distribución de la población y el crecimiento demográfico no fueron objeto de reflexión científica hasta el siglo XviII en que se produce la gran «Revolución Demográfica», en concomitancia con otras revoluciones socioeconómicas paralelas. Los grandes economistas y sociólogos de la época, como Adam Smith, Ricardo, Stuart Mill y otros, estudiaron el crecimiento económico de las naciones y el bienestar de la población. Pero la teoría más divulgada es la de Malthus, economista inglés, que en 1798 publicó el libro que le ha hecho famoso: Ensayo sobre el principio de la población, en el que, en síntesis, sostiene que mientras la población crece en proporción geométrica, los recursos lo hacen en proporción aritmética. Cuando escribió su libro, Malthus estaba impresionado por el rapidísimo crecimiento de la población en su época, lo que le llevó a adoptar una actitud pesimista sobre el crecimiento de la población, conocida como Maltusianismo, que en la segunda mitad del siglo xx adoptó la forma de Neomaltusianismo.

La Revolución Demográfica hace referencia al importantísimo cambio que se produjo en la demografía de los países europeos en el siglo XVIII, consistente en el rapidísimo crecimiento de la población europea durante la Modernidad. En 1929, el demógrafo americano Warren Thompson explicó el crecimiento de la población durante la Edad Moderna por la conocida teoría de la «Transición Demográfica», durante la cual el régimen demográfico tradicional de alta natalidad y mortalidad cambia a otro en el que durante algún tiempo la natalidad mantiene las altas tasas tradicionales y la mortalidad desciende rápidamente. La consecuencia fue el crecimiento rapidísimo de la población.

La Transición Demográfica, se inicia en Europa a comienzo de la Modernidad, en la época de los grandes descubrimientos geográficos y de las sucesivas revoluciones, agrícola, industrial, social, urbana, etc. que tienen lugar en esta época. Pero hasta finales del siglo xviII no se tuvo conciencia de lo que suponía el crecimiento de la población para la evolución sociocultural del continente. La Transición Demográfica ha sido uno de los fenómenos socioculturales más importantes de la historia reciente de la humanidad, aunque, sin duda, ha habido otras transiciones en épocas muy lejanas. Las transiciones demográficas han sido universales, aunque no simultáneas, ya que, como todos los movimientos demográficos espaciales, son diacrónicas. En Europa, la moderna transición demográfica suele darse por concluida a mediados del siglo xx, pero en otros continentes se hallaba en todo su apogeo al finalizar la centuria. 
En líneas generales, la situación demográfica de Europa con anterioridad a la transición se caracterizaba por las elevadas tasas de natalidad y mortalidad, muy próximas cuantitativamente entre sí, por lo que el crecimiento natural de la población era bajísimo. La transición propiamente dicha se desarrolló en varias fases que pueden reducirse a tres: a) descenso rapidísimo de la mortalidad manteniéndose la alta natalidad tradicional, b) lento declive de la natalidad continuando el descenso de la mortalidad, y c) rápido descenso de la natalidad y de la mortalidad.

La primera manifestación del cambio demográfico que da origen a la transición es la caída de la mortalidad. Desde un punto de vida estrictamente biológico, la vida del hombre sobre la tierra casi no ha consistido en otra cosa que en multiplicar sus esfuerzos para sobrevivir y sobreponerse al medio. Pero en los últimos doscientos cincuenta años, aquellos esfuerzos han producido resultados anteriormente impensables, como la disminución drástica de la mortalidad y el alargamiento de la vida.

El alargamiento de la vida; es decir, el incremento de la vida media o de la esperanza de vida al nacer, ha sido una constante de las sociedades occidentales durante la modernidad. Al comienzo de la transición, la vida media de una persona en Europa apenas llegaba a los cincuenta años. En los primeros años del siglo xxi, la esperanza de vida un europeo se acercaba a los 80 años y se incrementa un año cada cinco. Si no cambia la tendencia, a finales del siglo XXI, la esperanza de vida al nacer será, por lo menos de 100 años, lo cual tendrá repercusiones socioeconómicas y culturales impredecibles que obligarán a modificar profundamente los esquemas de los actuales sistemas socioculturales.

A comienzos de la transición, la mayoría de los países europeos registraban tasas de natalidad y de mortalidad superiores al 30\%o. A mediados del siglo $\mathrm{xx}$, completada ya la transición en estos países, las tasas de natalidad y mortalidad que registra el continente se han estacionado en torno al 11\%o, creándose un modelo de población estacionaria o de crecimiento cero. Estos países han entrado en una nueva transición demográfica caracterizada por el envejecimiento relativo de la población, cuyas repercusiones socioculturales son todavía impredecibles.

La caída de la mortalidad que caracteriza a la transición se manifiesta sobre todo en la disminución de la mortalidad infantil. El continente más desfavorecido es África, donde el $80 \%$ de la población muere antes de cumplir los sesenta años. Los países más favorecidos son Europa y los países ricos en los que la mayor parte de la población muere después de cumplir los sesenta años.

Como resultado de los avances de la medicina, la mortalidad general desciende en todo el mundo, aunque algunos países africanos registran todavía 
tasas de mortalidad próximas al 20\%o. Las causas de este retroceso son múltiples, pero en líneas generales hay que señalar tres: la mejora progresiva de las situaciones de penuria alimentaria, la erradicación paulatina de las enfermedades contagiosas y endémicas más mortíferas y la mejora de las condiciones de vida. En los países más desarrollados la causa principal de la mortalidad son las enfermedades degenerativas, como consecuencia del envejecimiento relativo de la población. En los menos desarrollados, por el contrario, las enfermedades infecciosas son todavía la principal causa de muerte.

Durante la mayor parte del siglo xx, los demógrafos relacionaron las elevadas tasas de mortalidad que se registraban en algunas partes del mundo con la carencia de recursos y las hambrunas periódicas. Actualmente, sin embargo, sin negar la importancia de las situaciones carenciales, naturales o provocadas, las dificultades para reducir la mortalidad se atribuyen a las malas condiciones ambientales, ya que los complejos patógenos solo se desarrollan si disponen de condiciones ecológicas favorables, especialmente de humedad y temperatura. El óptimo ecológico del hábitat de la mayoría de los microorganismos patógenos, como se ha dicho, se da con temperaturas medias de $30^{\circ} \mathrm{C}$ y una humedad superior al $50 \%$. De ahí que las zonas cálidas y húmedas sean las más proclives para el desarrollo de los complejos patógenos y, por lo tanto, para el desarrollo de enfermedades infecciosas.

Los esfuerzos del hombre para sobreponerse al medio natural, en competencia con otros organismos y microorganismos vivos, han sido constantes a lo largo del tiempo. Los complejos patógenos, según los describe Sorre, han estado presentes desde el principio en la historia de la Humanidad. Las pestes de diferente naturaleza, la viruela, la malaria, el cólera, el tifus, y otras enfermedades parasitarias y bacterianas han sido la principal causa de mortalidad humana, por su prevalencia y virulencia. Generalmente se desarrollan en un huésped y se propagan por medio de un vector.

Por otra parte, se sabe que la práctica totalidad de los microorganismos patógenos o sus vectores viven en el agua. De ahí la importancia del agua potable para el desarrollo sociocultural de las poblaciones. La Organización Mundial de la Salud (OMS) estima que todavía hay en el mundo 783 millones de personas que no tienen acceso al agua potable y más de dos mil quinientos millones de personas carecen de servicios sanitarios y conducciones de aguas residuales. Como muestran los datos de la OMS, las enfermedades ligadas a complejos patógenos se dan en los países menos desarrollados, muchos de los cuales se hallan en entornos geográficos tropicales. En cambio, en los países ricos prevalecen las enfermedades degenerativas, probablemente como consecuencia del alargamiento de la vida. 
Hasta la aplicación clínica de los antibióticos en la década de los años cuarenta del siglo $\mathrm{xx}$, la mayor parte de las enfermedades parasitarias e infecciosas eran mortales. Una de las causas de la propagación de las enfermedades parasitarias era la promiscuidad en que vivían personas y animales y las precarias condiciones de higiene doméstica. Las grandes reformas urbanas que auspició la Ilustración en Europa, a partir del siglo XviII tuvieron como propósito la mejora de las condiciones sanitarias de las ciudades, lo cual repercutió muy favorablemente en la erradicación de algunas enfermedades endémicas y en el retroceso de la mortalidad con que se inicia la transición.

La tasa de mortalidad hay que relacionarla con la estructura de la población. Los países más desarrollados muestran actualmente una tendencia hacia el incremento de la mortalidad como consecuencia del alargamiento de la vida. Por eso, desde una perspectiva sociocultural es conveniente conocer los estratos de población en los que la mortalidad tiene más incidencia. Generalmente, la tasa que se toma para establecer las comparaciones es la que se refiere a la población infantil.

Históricamente, la tasa de mortalidad infantil ha sido muy alta. Pero desde el último tercio del siglo $\mathrm{xx}$, en los países desarrollados la tasa de mortalidad infantil se ha reducido hasta casi desaparecer. Aparte de la atención médica, el descenso de la mortalidad infantil se debe también a las prácticas eugenésicas generalizadas, que abortan los fetos de difícil viabilidad o con malformaciones. En los países menos desarrollados la mortalidad infantil ha descendido también espectacularmente, aunque es todavía doce o quince veces mayor que en los desarrollados. En el año 2000, las Naciones Unidas establecieron los «Objetivos del Milenio», para mejorar las condiciones de vida de la población. Estos objetivos se cifraron en ocho puntos que deberían haberse conseguido ya en 2015: 1.- Reducir a la mitad la pobreza extrema y el hambre; 2.- Hacer que la enseñanza primaria fuera universal; 3.- Promover la igualdad entre hombres y mujeres; 4.- Disminuir en dos tercios la mortalidad infantil; 5.- Disminuir en tres cuartas partes la mortalidad materna; 6.- Combatir el SIDA, la malaria y otras enfermedades, hasta conseguir una generación sin VIH; 7.- Garantizar la sostenibilidad del medioambiente; y 8.- Fomentar la asociación mundial para el desarrollo. En 2011, la propia OMS dudaba que los «Objetivos del Milenio» pudieran alcanzarse en la fecha prevista.

Como se ha dicho anteriormente, la natalidad ha disminuido constantemente desde la segunda etapa de la Transición y constituye uno de los elementos característicos de la misma. Al principio de la Transición, los países europeos, tenían por término medio una natalidad del 35\%o, que en algunos países llegaba al 40\%o, Al finalizar el proceso de cambio demográfico que en 
su conjunto se ha desarrollado a lo largo de unos doscientos cincuenta años, las tasas de natalidad se habían estacionado en torno al 10\%o.

En principio, la caída de la natalidad es consecuencia de la disminución de la fecundidad o número de hijos por mujer, que en la especie humana es un fenómeno biológico condicionado por factores socioculturales. Lo mismo que se ha hecho con las tasas de natalidad, se ha intentado determinar también el número máximo de hijos por mujer. La «fecundidad natural o biológica», cubre por término medio, unos 35 años. Suponiendo que hubiera un embarazo por año, esa sería la fecundidad máxima. Sin embargo, salvo casos particulares, probablemente no se ha dado nunca esa situación en las sociedades humanas. Teniendo en cuenta la infecundidad patológica, los periodos de lactancia y la naturaleza de las estructuras socioculturales en las que tiene lugar la reproducción, la fecundidad biológica de la especie humana no debe ser superior a 20 hijos por mujer, aunque hay casos particulares de mujeres que han dado a luz a más de 20 hijos. La fecundidad más elevada se registra actualmente en África, donde África Occidental registra 5'7 hijos por mujer; África Oriental, 5'5; África Central, 5’9, y algunos países, como Níger llegan a 7'l hijos por mujer.

El descenso de la mortalidad y de la natalidad son fenómenos inherentes a la Transición Demográfica. Pero mientras los países de cultura occidental dieron por concluida la transición, como se ha indicado, a mediados del siglo xx, los países menos desarrollados, muchos de los cuales habían formado parte de los modernos imperios coloniales, comenzaron de hecho su transición poco antes de alcanzar la independencia, en la segunda mitad del siglo xx y se hallan actualmente en el momento culmen de la misma. La transición occidental se prolongó a lo largo de más de doscientos cincuenta años. Sin embargo, las políticas demográficas propuestas por los organismos internacionales pretenden que los países menos desarrollados reduzcan este periodo a menos de un siglo, de manera que la transición esté terminada en el año 2050.

Las políticas demográficas recomendadas por los organismos internacionales van dirigidas sobre todo a los países menos desarrollados para que tomen medidas a fin de controlar las dos variables fundamentales del crecimiento demográfico, la natalidad y la mortalidad. Pero estas dos variables no explican por sí solas el cambio del modelo demográfico tradicional. Lo que realmente cambió durante la transición fue el sistema sociocultural europeo, con su cortejo de subsistemas sociales, económicos demográficos políticos, etc. que había imperado en el continente durante milenios. Las actuales políticas demográficas olvidan con frecuencia que ambos fenómenos demográficos se hallan siempre condicionados por el sistema sociocultural en el que se inscriben y que mientras éste no cambie, las políticas demográficas recomendadas no tendrán éxito. 
La mayoría de los países menos desarrollados se hallan actualmente en la primera fase de la transición, con tasas de natalidad muy elevadas que, en algunos casos superan el $40 \%$, mientras que la mortalidad media, aunque tiende a decrecer, supera en algunos países el $16 \%$, por la incidencia de la mortalidad perinatal, de la malaria y del VIH, que desempeñan, respecto de la mortalidad, el mismo papel que en el siglo xviII desempeñaban en Europa, la viruela, el tifus y las pestes.

Uno de los efectos de la transición demográfica en Europa fueron los grandes movimientos de población. La presión demográfica que se suscitó entonces en muchos lugares promovió algunas de las grandes corrientes migratorias de la época moderna. De una parte, se produjo la afluencia de grandes masas de población rural hacia las ciudades, coincidiendo con la derogación socioeconómica del antiguo régimen, el inicio del capitalismo y la incipiente industrialización. En el siglo xvIII, las viejas ciudades europeas, muchas de ellas con una historia milenaria, adquirieron nuevas funciones como consecuencia de las grandes revoluciones socioeconómicas de la Modernidad, lo cual las convirtió en centros de atracción demográfica. Por otro lado, la Modernidad produjo un cambio en la división geopolítica del mundo. Los viejos imperios español y portugués cedían ante los nuevos imperios emergentes construidos, con muy pocas excepciones, sobre territorios semivacíos, principalmente en América y Australia, que atrajeron a millones de emigrantes europeos.

La doble corriente de movimientos de población que acompañaron a la transición europea, desde las áreas rurales hacia las ciudades y desde Europa a otros continentes, se repite actualmente en los países que se hallan inmersos en sus respectivas transiciones. Aunque los hechos son parecidos, las circunstancias geopolíticas y geoeconómicas del mundo no son las mismas. Los cambios socioculturales, económicos y políticos que acompañaron a la transición europea, no se dan actualmente en ninguno de los espacios geográficos afectados por la transición. Ya no existen espacios vacíos susceptibles de ser ocupados por los inmigrantes y la globalización de la economía ha generalizado las economías de escala, antaño desconocidas.

Lo mismo que había sucedido en Europa durante la Modernidad, en los años sesenta del siglo Xx, cuando las antiguas colonias alcanzan su independencia, se produjeron en los nuevos países independientes grandes flujos de población desde el mundo rural hacia las ciudades, muchas de las cuales habían sido creadas ex novo por las administraciones coloniales. En este caso, el éxodo rural no fue consecuencia de un cambio de régimen socioeconómico, como había sucedido en Europa, sino que obedeció a un deseo mimético de habitar en las ciudades, producido por el espejismo de la etnoculturización 
durante la ocupación colonial. En los países menos desarrollados, las ciudades millonarias, algunas de las cuales figuran entre las más pobladas del mundo, como Delhi 23 millones; Karachi, 21 mill.; Mumbai 20 mill.; Calcuta, 15 mill.; El Cairo, 15 mill.; Lagos, 13 mill., se han convertido en focos de pobreza y marginación social.

\section{LAS TEORÍAS DE LA POBLACIÓN, MALTHUSIANISMO-ANTIMALTHUSIANISMO}

Aunque desde principios de la Edad Moderna hubo pensadores que se ocuparon de relacionar el crecimiento de la población con la disponibilidad de recursos, hasta el siglo xVIII, como se ha dicho anteriormente, no se plateó realmente la cuestión del crecimiento de la población. Por regla general, las sociedades antiguas eran poblacionistas, dado que a mayor población correspondía mayor potencia militar, mayor recaudación de impuestos y mayor fuerza de trabajo. Petty, un médico y economista inglés, sostuvo a finales del siglo XVII que la mayor riqueza de un país era su población. Llegó a afirmar que «una población escasa es realmente pobre. Una nación con ocho millones de habitantes, escribía, será más del doble de rica que otra igualmente extensa, pero que no tenga más que cuatro millones». Algo más tarde, Adam Smith, en su estudio sobre las causas de la riqueza de las naciones, decía que «la señal más decisiva de la prosperidad de un país nos la da el aumento del número de sus habitantes». El optimismo de Smith contrasta con el pesimismo de otros economistas de la época, como David Ricardo y Stuart Mill, que siguen total o parcialmente a Malthus.

Desde la época de Malthus, la mayoría de los economistas y sociólogos se han ocupado del crecimiento de la población, aportando hipótesis sociales, económicas, biológicas y culturales, en gran parte recogidas por. Sidney H. Coontz, en un libro titulado Teorías Económicas y su Interpretación Económica, publicado en 1957.

Según este autor, las teorías biológicas explican el crecimiento de la población humana como el de cualquier otra población animal o vegetal. La población crece mientras hay recursos y disminuye cuando éstos escasean. Las teorías biológicas pueden explicar el crecimiento de las poblaciones animales, pero solo parcialmente pueden aplicarse al hombre, que es capaz de sobreponerse al medio natural desarrollar técnicas productivas cada vez más eficaces y establecer relaciones comerciales, que le permiten hacer acopio de recursos procedentes de lugares muy lejanos. No obstante, las teorías biológicas repuntan periódicamente y se ponen de actualidad, sobre todo cuando se relacionan con el hambre. 
En 1841, el demógrafo Doubleday publicó su libro La verdad sobre la ley de la población en el que sostiene que la fertilidad está en relación con el consumo de proteínas, en lo cual coincide parcialmente con la teoría de Josué de Castro, La Geografía del Hambre, emitida un siglo más tarde, en 1952, según la cual las dietas de hambre favorecen la fertilidad, mientras que la sobrealimentación conduce a la esterilidad. M. Thomas Sadler, a su vez, publicó en 1830, La Ley de la Población, donde sostiene dos principios: que la verdadera ley de población es que la fertilidad varía inversamente a la densidad de población. De la misma época son los estudios matemáticos de Verhulst, quien llega a la conclusión de que el crecimiento de la población sigue una curva logística o sinusoidal que, con modificaciones, se utiliza todavía para hacer las previsiones del crecimiento demográfico.

Las teorías culturales intentan explicar el crecimiento de la población por factores culturales, lo cual hace que la lista de estos factores sea inacabable. Por eso, las teorías culturales suelen referirse únicamente a las actitudes y comportamientos de las sociedades respecto de la natalidad, dando por supuesto que es un fenómeno biológico que puede regularse voluntariamente. Los factores, materiales (económicos) e inmateriales (valores) que mueven la voluntad de las personas para incrementar o disminuir la fecundidad son de índole cultural. Todas defienden que el crecimiento vegetativo de la población depende del grado de desarrollo sociocultural y bienestar alcanzados. Estadísticamente y a escala regional, se relaciona el problema del hambre en el mundo, que es un indicador de bienestar social, con el crecimiento de la población. Josué de Castro, anteriormente citado, sostiene que la pobreza estimula la fecundidad. Pone de relieve que los países menos desarrollados son los que presentan una fecundidad más alta, al contrario de lo que sucede en los países más desarrollados en los que la fecundidad es muy baja y no alcanza el grado de reemplazamiento generacional. Josué de Castro explica el hambre en el mundo como consecuencia del «déficit cultural» en el que se hallan inmersas las sociedades poco desarrolladas, en comparación con las más desarrolladas. Este déficit se manifiesta por un conjunto de circunstancias, como la escasa educación, la pobreza, la deficiente organización social, la incidencia de enfermedades endémicas, etc. que podrían corregirse dedicando recursos económicos, sociales y políticos para ello.

A finales del siglo XIX el demógrafo francés Arsène Dumont explicó el crecimiento de la población por la teoría de la «Capilaridad Social», que fue casi unánimemente aceptada hasta mediados del siglo xx. Para Dumont, el principio que regula el crecimiento de las poblaciones humanas es el de la capilaridad social, cuyo fundamento es la jerarquía social. En las sociedades abiertas, en las 
que las estructuras sociales son permeables, la posibilidad de ascender en la escala social reduce la fecundidad. La crianza y educación de los hijos exigen esfuerzo y cuantos menos hijos tengan las familias, más recursos podrán destinar a su educación, que es lo que asegura el ascenso en la escala social. Según Dumont, la natalidad sería inversamente proporcional a la capilaridad social.

La afirmación de Dumont parece cumplirse si se repara en la historia social de Europa. En la sociedad estamental que rigió en Europa hasta la Edad Moderna, era prácticamente imposible que una persona cambiase de estatus social. Los estamentos eran estructuras socioculturales cerradas e infranqueables. La nueva figura del ciudadano con igualdad de derechos y deberes que establece la Declaración de los Derechos del Hombre de 1789, frente al tradicional sistema social de los estamentos, es fundamental para comprender el cambio de ritmo de la natalidad durante la transición. En el antiguo régimen, la instrucción y la educación eran valores de escasa trascendencia para el común de la gente, cuya condición social venía determinada por la de la familia de origen. El que una familia tuviera pocos o muchos hijos no repercutía en la condición social de éstos.

Con la instauración del nuevo régimen, la proclamación y consolidación de los derechos del hombre, y el reconocimiento de la igualdad de derechos y obligaciones, la sociedad, que había permanecido fuertemente estructurada en clases cerradas durante más de mil años, se abre y otorga a todos los ciudadanos la misma igualdad de oportunidades. La educación, ya no es un valor inservible para la mayoría de las personas, sino un instrumento de promoción social. Según Dumont, las familias restringen el número de hijos para poder darles una mejor educación con la que mejorar sus condiciones de vida. Con más o menos variantes, todas las teorías culturales utilizan los mismos argumentos sociales, económicos y jurídicos, para explicar la disminución de la natalidad. En las sociedades en las que la herencia se reparte entre todos los hijos, el patrimonio familiar se reduce con cada transmisión y en pocas generaciones puede llegar a desaparecer. De ahí la tendencia de las familias pudientes a tener pocos hijos y a consensuar matrimonios de interés, a fin de conservar el patrimonio. En algunas regiones la institución del heredero único que, según las regiones puede ser el primogénito u otro de los hijos, es una forma de mantener la unidad del patrimonio familiar.

La teoría de la capilaridad y otras basadas en el cambio social tuvieron gran aceptación en la primera mitad del siglo xx. El economista alemán Ludwig Brentano, sostenía que la natalidad disminuía al mejorar las condiciones de vida. En esta misma línea de pensamiento, durante la segunda mitad del siglo Xx, se intentó explicar el crecimiento de la población por los cambios sociales. Por primera vez se habló de "paternidad responsable», en el sentido de que 
los hijos debían recibir una educación congruente con las circunstancias socioculturales del momento a fin de mantener, e incluso superar, el estatus socioeconómico de los padres.

En el cambio de centuria, las teorías acerca de la disminución de la natalidad se centran en el individualismo de las sociedades modernas, en los profundos cambios que afectan a la estructura familiar, como la emancipación de la mujer, el creciente protagonismo de ésta en la sociedad y el incremento imparable de la urbanización. Históricamente, la natalidad ha sido una cuestión que afectaba por igual al padre y a la madre. Pero en algunas culturas se han desarrollado corrientes de pensamiento que ven la natalidad como un fenómeno inherente a los derechos de la mujer, dueña de su propio cuerpo. Por otra parte, las modernas técnicas de fecundación extrauterina y las circunstancias en que se produce complican enormemente la elaboración de teorías acerca del descenso de la natalidad en los países más avanzados.

Las teorías económicas, finalmente, sostienen que únicamente los factores económicos regulan el crecimiento de la población, ya que ésta depende, para subsistir, de los recursos disponibles. Sin embargo, la disponibilidad de recursos guarda una estrecha relación con la naturaleza de las necesidades a satisfacer y ya se ha visto que las necesidades humanas, incluso las primarias, admiten infinidad de grados. Por otra parte, las nuevas tecnologías han incrementado la productividad en términos insospechados hace tan solo unos pocos años y los transportes permiten satisfacer necesidades que se originan lejos de los lugares donde se obtienen los recursos. De ahí que las teorías económicas acerca del crecimiento de la población hayan caído en desuso substituidas por teorías culturales.

La diversidad sociocultural del mundo ha obligado a elaborar un sin fin de proposiciones de políticas demográficas, sin que ninguna de ellas pueda aceptarse con carácter universal. Frente al neomaltusianismo, de marcado carácter macroeconómico, han surgido teorías, como las propuestas por H. Leibenstein, G. S. Becker y R. A. Easterlin y otros muchos, que explican el descenso de la natalidad en la evolución de las familias. Muchas de estas teorías se basan en el «grado de utilidad» o «no-utilidad» que las familias encuentran en tener un hijo más, ya sea por razones de promoción social, por la subordinación de la mujer a la crianza del nuevo hijo, por razones de estructura familiar o por el coste de la educación que se desea dar al nuevo hijo.

Todas las corrientes del pensamiento económico y sociocultural, desde el Marxismo al Liberalismo, han opinado sobre el crecimiento de la población. El Marxismo fue originalmente antimalthusiano. Para Marx, el hambre, la falta de trabajo, la pobreza, etc. no eran consecuencia de la superpoblación, 
sino de las injusticias del Capitalismo. Algunos teóricos del Marxismo explican la caída de la fecundidad por la existencia de la propiedad privada y el reparto de la herencia. Otros, como Martínez Peinado, sugieren que existe relación entre el Capitalismo y la superpoblación, ya que esta corriente ideológica favorece exceso de fuerza laboral a fin de rebajar su coste.

A lo largo del siglo xx, las teorías, antimalthusianas, y neomalthusianas han adquirido periódicamente preeminencia, tanto en el ámbito ideológico del Liberalismo, como del Socialismo, a tenor de las políticas de población recomendadas por los organismos internacionales. Keynes, uno de los grandes economistas del siglo xx, llegó a afirmar en el periodo de entreguerras que «la población es la causa de la inestabilidad social». Aunque más tarde cambió de opinión, el neomaltusianismo ha sido la teoría de la población más difundida en las últimas décadas del siglo xx. Las nuevas sociedades urbanas habían reducido su fecundidad como consecuencia de las particularidades del urbanismo moderno. A su vez, las sociedades tradicionales, especialmente las sociedades rurales, que veían en los hijos una fuente de ingresos, han cambiado su comportamiento respecto de la fecundidad a medida que sus modos de vida se acercan a los urbanos. Para algunos keynesianos, en cambio, la teoría de la capilaridad social sigue vigente, ya que el coste de la educación y la aspiración a mejorar las condiciones de vida son factores de disminución de la natalidad.

Después de la Segunda Guerra Mundial se produjo un repunte espectacular de la natalidad, lo que se conoce como el baby boom que algunos sociólogos relacionan con la desmovilización de las tropas que habían participado en el conflicto. Extrapolando la tendencia del crecimiento de la población observada en un corto periodo de tiempo se llegó a la conclusión de que la densidad de población del planeta sería insoportable en menos de un siglo, debido, sobre todo al rápido crecimiento de la población de los países menos desarrollados. En la década de los años sesenta del siglo xx, durante la que se produce la independencia de la mayor parte de los países que habían formado parte de los modernos imperios coloniales, se observa que los países menos desarrollados se caracterizan por sus elevadas tasas de natalidad. Si se quería que estos países alcanzasen un mayor grado de desarrollo, había que adoptar políticas demográficas restrictivas de la natalidad. El neomaltusianismo se impuso definitivamente durante la segunda mitad del siglo xx, avalado por las recomendaciones de organismos internacionales, como el Banco Mundial, las Naciones Unidas, la Fao, etc. Los argumentos para estas recomendaciones son fundamentalmente económicos y se basan en las aportaciones de los demógrafos Coale y Hoover, que, en 1958, publicaron un libro titulado Crecimiento de la Población y Desarrollo Económico en los Países Menos Desarrollados. Para estos autores, la 
necesidad de reducir la natalidad se justifica por el elevado coste que genera la satisfacción de sus necesidades no productivas, como la salud y la educación.

Frente al neomaltusianismo preconizado por los organismos internacionales surge, en el último tercio del siglo xx, el antimalthusianismo, cuyos representantes más conspicuos son Colin Clark, J. L. Simon y Alfred Sauvy. Para estos demógrafos, el crecimiento demográfico es la base del progreso económico. La presión demográfica estimula la iniciativa, incrementa la productividad e introduce nuevas formas de organización social que incrementan el bienestar. Para Simon el recurso más importante de la economía es la población y como Clark, sugiere que la presión demográfica obliga a mejorar las infraestructuras y a innovar. La historia de la humanidad muestra que el crecimiento de la población ha ido siempre acompañado de crecimiento económico. Para Sauvy no hay desarrollo económico sin crecimiento de la población. El crecimiento cero, propio de las poblaciones estacionarias, es contraproducente, porque a largo plazo conduce al envejecimiento relativo de la población. La superpoblación sería un concepto relativo que es preciso valorar en sus justos términos en cada lugar y en cada momento.

\section{EVOLUCIÓN SOCIOCULTURAL Y SOSTENIBILIDAD}

Después de la Segunda Guerra Mundial, a partir de la información estadística disponible en aquel momento, se hicieron proyecciones para calcular el volumen probable de población que tendría el mundo en las décadas posteriores. Surgieron así teorías catastrofistas de corte neomalthusiano que predecían hambrunas generalizadas antes de acabar el siglo xx, que no se confirmaron.

Abandonadas las teorías catastrofistas, una de las preocupaciones socioculturales más generalizadas en el mundo actual es la de la «sostenibilidad». La experiencia de más de dos siglos de desarrollo económico muestra que las teorías de Malthus no se han cumplido. Desde entonces, la productividad ha ido en aumento y el bienestar social ha crecido sin parar aunque, como sucede siempre con los progresos socioculturales, sus efectos no han sido universales ni simultáneos en todo el mundo. La pregunta que se hacen científicos, sociólogos, economista, políticos etc., es si el ritmo del crecimiento socioeconómico, tal como se manifestó durante la segunda mitad del siglo xx, podrá mantenerse indefinidamente.

Una ligera reflexión acerca de esta cuestión induce a una respuesta negativa. Aparte de la adecuación de los sistemas socioculturales a las circunstancias técnicas de cada momento, el crecimiento económico se hace a expensas 
de materias primas y energía. En tanto que recursos, ambas no son ilimitadas. Por lo tanto, el crecimiento, que depende de ellas, no lo puede ser tampoco. Si se produce escasez o carencia de materias primas o de energía, el bienestar social decaerá y se producirá una regresión sociocultural de la humanidad. Desde otro punto de vista, la sobreexplotación de los recursos naturales para mantener e incrementar el nivel de vida causa un daño irreparable al planeta por la degradación medioambiental que produce. Para salvar esta situación, en las últimas décadas del siglo xx, las Naciones Unidas propusieron un modelo de desarrollo sostenible que consiste en «satisfacer las necesidades del presente sin comprometer las necesidades de las futuras generaciones». El término aparece por primera vez en el Informe Brundtland elaborado en 1987 para las Naciones Unidas por una comisión de expertos encabezada por la política sueca del mismo nombre. Entre otras medidas, el informe propone incrementar el control demográfico, referido principalmente a las tasas de natalidad. Desde entonces las Naciones Unidas han organizado diferentes conferencias sobre Población y Desarrollo entre la cuales hay que citar la Conferencia de El Cairo de 1994, por la importancia de los acuerdos que en ella se tomaron respecto del control de la natalidad, y «conseguir antes de 2015 el acceso universal a los servicios de salud reproductiva, incluyendo la planificación familiar y la salud sexual». El principio general adoptado en El Cairo fue que para promover el desarrollo hay que controlar la población.

La sostenibilidad guarda una estrecha relación con las necesidades que el hombre desea satisfacer. El hombre utiliza ciertas técnicas y desarrolla y adopta formas concretas de organización social con el fin de satisfacer sus necesidades. Tanto las técnicas como las formas de organización pueden ser variadísimas y todo ello, en conjunto, da contenido a los sistemas socioculturales. También se ha visto que el concepto de necesidad, sobre todo en los sistemas socioculturales muy evolucionados, es subjetivo. Hay unas necesidades primarias que vienen requeridas por las características biológicas de los seres vivos, entre los que se incluye el hombre, y las particularidades fisiológicas de sus organismos. Pero la ethología animal no tiene nada que ver con la humana. El hombre, por su condición de ser racional, no actúa guiado por el instinto, sino por la razón, gracias a la cual se halla en condiciones de controlar el instinto.

Si después de una evolución sociocultural de cientos de miles de años, las poblaciones humanas no tuvieran más finalidad que satisfacer sus necesidades primarias, alimentación, vivienda y vestido, la cuestión de la sostenibilidad no se hubiera planteado ni siquiera a nivel teórico. Pero, como indica Le Lannou, el hombre tiene que satisfacer también un conjunto de necesidades secundarias o adquiridas, que nosotros denominamos culturales, cuyo modo de satis- 
facerse constituye el meollo de la Geografía Social y Cultural. Por su propia naturaleza, el índice de saturación de las necesidades primarias es bajo y se alcanza enseguida. El problema surge cuando se trata de satisfacer necesidades adquiridas, que, por su propia naturaleza, expresan un deseo cultural y carecen de umbral de saturación: pueden crecer hasta el infinito.

Todas las hipótesis y teorías sobre la sostenibilidad se basan en la certeza de que los recursos que el hombre utiliza serán cada vez más escasos, con la particularidad de que los más fuertes acabarán despojando a los más débiles de los recursos que necesitan para la vida. La creciente extensión de la pobreza en el mundo sería una prueba de ello. La Comisión Mundial del Medio Ambiente y del Desarrollo, de las Naciones Unidas, creada en 1988, estimó que el 20\% de la población mundial, los países ricos, consumían el $80 \%$ de los recursos mundiales, condenando así a la pobreza a una gran parte de la humanidad.

Si se acepta que la materialidad corporal de cada ser vivo está formada por una porción de elementos procedentes del sistema global, que podemos denominar medio ambiente, el límite del número de seres vivos vendría determinado por la cantidad de elementos disponibles en el sistema, independientemente del tamaño y complejidad morfológica de esos seres. Puesto que el mundo espacio-temporal es finito, la cantidad de elementos que lo constituyen debe ser también finita y por lo tanto el número de seres que de ello se derivan debe tener un límite. Si en lugar de considerar el sistema medioambiental terrestre, el planeta tierra se entiende como parte de un sistema medioambiental cósmico, los límites anteriores se hacen inconmensurables. En el estado actual de nuestros conocimientos, todas las estimaciones basadas en este tipo de consideraciones son más utópicas que reales.

Otra cuestión distinta es el ritmo por el que los organismos vivos extraen del medio los elementos que precisan para vivir. La Comisión Mundial del Medio Ambiente señaló ya en 1988, que «en muchas partes del mundo los recursos disponibles no pueden sostener tasas de mejora progresiva de las condiciones de vida, no solo en alimentación, sino también, en atención médica, educación, energía, vivienda, etc.» La misma Comisión, en reuniones posteriores ha llegado a la conclusión de que si toda la población del mundo tuviese el mismo nivel de consumo que los países desarrollados, se necesitarían los recursos de tres tierras.

La mayor parte de los recursos orgánicos que el hombre consume y las fuentes de energía que utiliza tienen su origen en el sol, cuya energía es utilizada por las plantas mediante la función de fotosíntesis para fijar el carbono de la atmósfera y producir materia orgánica. La vida actual en la tierra depende de la fotosíntesis. Los biólogos han calculado la cantidad de materia orgánica que 
produce el planeta tierra, con resultados muy dispares. En cualquier caso, la cantidad media de carbono fijado por fotosíntesis, según los diferentes cálculos, y la producción de materia orgánica son enormes: alrededor de 1 ' 55 x $10^{11}$ toneladas anuales; esto es, unas $20 \mathrm{Tm}$. de biomasa por persona. El consumo medio de alimentos varía, según las diferentes zonas geográficas y culturas del planeta, entre una y tres toneladas. En principio, pues, no debería haber escasez de alimentos en el mundo. La escasez se debe a una mala distribución geográfica de los espacios productivos, a la apropiación geopolítica de grandes espacios exclusivos para formar estados territorialmente muy extensos y a la asociación cultural de las poblaciones con un escaso número de especies cultivadas. Sin embargo, la citada Comisión de las Naciones Unidas sigue manteniendo la teoría de que la tierra ha superado ya la carrying capacity, o capacidad de soportar el actual volumen de población de la tierra.

El concepto de sostenibilidad plantea otras muchas cuestiones fundamentales para la Geografía Social y Cultural. De acuerdo con las estadísticas del consumo, las sociedades más desarrolladas se caracterizan por estar en condiciones de satisfacer selectivamente las necesidades primarias y un elevado volumen de necesidades secundarias. Los sistemas socioculturales avanzados se caracterizan por el hiperconsumo de bienes y servicios, que no son estrictamente necesarios para la vida, pero son manifestaciones culturales del bienestar social. Una de las definiciones clásicas de clase social establece que una persona pertenece a la clase social en la que los demás la sitúan, y lo hacen a través de signos externos de pertenencia a dicha clase. Las culturas muy desarrolladas y particularmente las occidentales, han generado también sociedades de consumo, que no consumen lo que objetivamente necesitan, sino lo que imaginativamente creen necesitar en función de la calidad de vida a la que aspiran. El hiperconsumo de bienes y servicios para satisfacer necesidades secundarias o adquiridas guarda una estrecha relación con los sistemas de valores que cada cultura y cada sociedad adoptan. La sostenibilidad tiene también un sentido ético que se proyecta en la mayoría de las propuestas que los organismos internacionales hacen en defensa de la sostenibilidad, como el control de la natalidad, la conservación del medio ambiente, etc.

En los años setenta del siglo xx, las Naciones Unidas impulsaron el Proyecto 21 , que aludía al siglo próximo y se proponía hacer recomendaciones para garantizar la sostenibilidad del planeta y mejorar las condiciones de vida de la población. La creación de la Comisión de Medio Ambiente en 1983 hizo que las recomendaciones, inicialmente se referían al crecimiento de la población, abarcasen la practica totalidad de las actividades humanas, que cada vez se hallan más condicionadas por las doctrinas ecologistas. 
Las teorías neomalthusianas del crecimiento excesivo de la población, tan en boga en el último tercio del siglo xviII y que dieron lugar a importantes discusiones académicas, como las sostenidas por Ehrlich y Ehrlich de una parte, partidarios de limitar la población, y Simon, Clark y Sauvy, de otra, han perdido la beligerancia que antes tuvieron, aunque se presentan como soluciones regionales al crecimiento de la población. El trasfondo ético de las teorías ecologistas que alimentan la sostenibilidad reside en el abuso que las sociedades desarrolladas practican respecto de los recursos disponibles para el sustento de la humanidad. El concepto de propiedad actualmente utilizado proviene del derecho romano, que definía la propiedad como el ius fruendi, utendi et abutendi, o el derecho de usar, disfrutar y abusar de las cosas. El abuso consiste en ir más allá del uso que racionalmente debe darse a las cosas. En este sentido, el uso inadecuado o desproporcionado de cualquier cosa o bien es éticamente rechazable. La sobreexplotación de los recursos naturales, la degradación por el uso inadecuado del medio natural, etc. son muestras de abusos ecológicos.

A lo largo del siglo xx la población mundial pasó de 1.600 a 6.000 millones. Aunque se ha producido un descenso en la tasa de crecimiento de la población, ésta sigue aumentando a razón de unos 70 millones de personas cada año, por lo que puede duplicarse de nuevo en pocas décadas. La Comisión Mundial del Medio Ambiente y del Desarrollo señaló en 1988 la insostenibilidad de este ritmo de crecimiento y las consecuencias catastróficas de esta tendencia. Pero desde entonces la misma Comisión ha modificado el carácter universal de sus primeras conclusiones.

El crecimiento acelerado de la población mundial en la segunda mitad del siglo xx ha recibido el nombre genérico de explosión demográfica. Se compara el crecimiento de la población mundial con los efectos destructivos de una explosión. Después de la segunda guerra mundial, cuando la natalidad de los países que habían participado en la guerra experimentó un notable repunte se habló de baby boom.

Las hipótesis de crecimiento de la población mundial para mediados de la centuria varían entre poco más de 12.000 millones y algo menos de 8.000 . La horquilla de 4.000 millones entre el volumen máximo y mínimo de población, que equivale al $50 \%$, es demasiado grande para ser fiable. El verdadero problema del crecimiento de la población no parece estar en el número, sino en las condiciones de vida de la población y en la dificultad de atajar la pobreza, como dice Sachs, Director del Proyecto del Milenio de las Naciones Unidas. La sostenibilidad de la población no va a depender tanto del número de personas que haya en cada lugar, como de la naturaleza de las necesidades culturales que la sociedad demande en cada caso y de los sistemas demográficos de nueva implantación. 
LOS SISTEMAS DEMÓGRAFICOS. ESTABILIDAD E INESTABILIDAD DE LOS SISTEMAS DEMOGRÁFICOS

Las estadísticas referentes a la población mundial suelen presentar el volumen de la misma y su estructura y distribución, pero apenas reparan en el hecho de que la población no es un conjunto discreto de individuos, sino que constituye un sistema demográfico subdividido en subsistemas.

Como se ha dicho al principio, los sistemas demográficos se construyen a expensas de la población que en cada momento vive en las diferentes porciones de la superficie terrestre. En líneas generales, las sociedades humanas no son solo conjuntos de individuos, sino sociedades organizadas que subsisten merced al sistema demográfico adoptado, cuya dinámica obedece a principios estructurales endógenos y a influencias externas. Para que un grupo de personas pueda considerarse sociedad, es necesario que tengan una idea compartida sobre el fin para el que se asocian y que adopten algún tipo de organización. La finalidad de los sistemas demográficos es satisfacer las necesidades primarias y secundarias de la población, para lo cual interaccionan con otros sistemas más o menos complejos, como los sistemas económicos, territoriales, sociales, políticos, etc. para constituir, en su conjunto, los sistemas socioculturales.

Los sistemas demográficos se miden por una escala de magnitudes en relación con el número de elementos que contienen, la naturaleza de las necesidades que deben satisfacer y su ámbito territorial de acción. La escala de magnitudes va desde el mínimo grupo social, que puede ser la familia, hasta un estado o un grupo de estados vinculados por lazos culturales. La naturaleza de las necesidades que deben satisfacer varía según el régimen económico adoptado y el ámbito territorial de acción puede ser desde un barrio urbano hasta un continente o zona geográfica.

Esto permite clasificar los sistemas demográficos en macrosistemas y microsistemas. La adopción de un sistema demográfico es necesaria para el cumplimiento del fin que las sociedades humanas se proponen alcanzar.

Dada la variedad de sociedades y de ámbitos territoriales en los que se manifiestan, no existen dos sistemas demográficos idénticos. La razón es que hay muchas clases de territorio y muchos tipos de sociedades y el propósito de estas, aun con un denominador común, que es la satisfacción de las necesidades, no es siempre el mismo, porque las necesidades culturales pueden ser diferentes en cada caso concreto. 
FIGURA 1

INTERACCIÓN DE LOS SISTEMAS DEMOGRÁFICOS

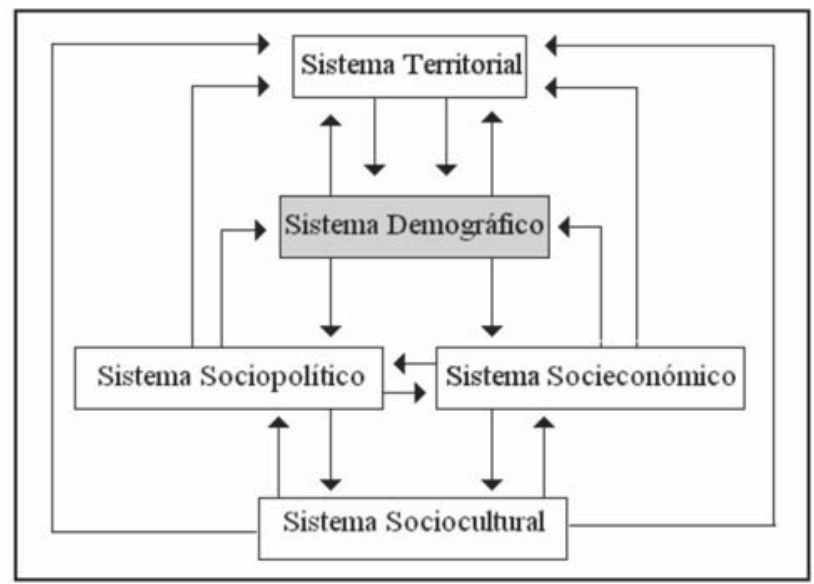

Fuente: elaboración propia.

El territorio no es simplemente el soporte de la población. Las relaciones población-territorio tienen un evidente carácter biocenótico; es decir, son interdependientes. Los ecólogos saben que la existencia de los seres vivos no es ajena al espacio en el que viven, por eso estudian la distribución espacial de las especies animales y vegetales y el grado de asociación de unos individuos con otros. Para ello utilizan artificios estadísticos como el cálculo de la distancia al vecino más próximo, lo cual equivale a determinar indirectamente la densidad de las respectivas poblaciones en un área dada. Esta área constituye, para las especies estudiadas, su espacio natural de vida o en términos más precisos, su carrying capacity, que se define como «la capacidad de un espacio dado para soportar un determinado número de individuos», lo cual ha hecho que algunos economistas y sociólogos hablen del óptimo de poblamiento y presión demográfica.

La carrying capacity, el óptimo de poblamiento y la presión demográfica, tienen un evidente significado ecológico, y se han utilizado para explicar razonablemente la distribución de los seres vivos en la superficie terrestre. Pero cuando dichas teorías se aplican a la distribución de las poblaciones humanas, surge la naturaleza sociocultural del hombre que desmiente la universalidad de las mismas. Los organismos vivos pueden adaptarse a los diferentes ambientes, pero el hombre socialmente organizado, no solo se adapta al medio en 
el que vive, sino que es capaz también de modificarlo con arreglo a sus conveniencias e incluso de crear su propio ambiente social.

Aunque las relaciones biocenóticas entre la población y el territorio son innegables, el concepto de carrying capacity no es, pues, aplicable a las poblaciones humanas. Los sistemas demográficos funcionan como subsistemas de los sistemas territoriales, los cuales son percibidos por aquellas poblaciones como espacios de vida. Estos espacios pueden ser tan reducidos o tan amplios como se quiera, dependiendo del grado de movilidad de la población. Los espacios de vida se caracterizan por sus respectivos sistemas demográficos. Estos no tienen el mismo significado en las grandes metrópolis que en los pequeños núcleos de poblamiento rural o en un barrio intraurbano.

En un mundo caracterizado por la globalización, la población no es ya una variable dependiente de los recursos actualmente disponibles, sino una variable independiente, es decir, causal y explicativa del hecho, como afirmaba Vidal de la Blache diciendo que la naturaleza ofrece siempre posibilidades al hombre. Esta afirmación fue certeramente corregida por Derruau, precisando que las posibilidades no están en la naturaleza, sino en el hombre. No se trata de saber si un determinado agregado de población puede mantenerse en función de los recursos, técnicas y formas de organización actuales, sino de conocer si el grupo tiene suficiente capacidad endógena para generar los flujos de inputs necesarios para que el sistema territorial del que forma parte funcione y se desarrolle. Por eso, solamente se puede hablar de superpoblamiento y subpoblamiento refiriéndolos a la eficacia del respectivo sistema demográfico.

Generalmente la población se estudia en grandes aglomerados: continentes, estados, regiones, ciudades, etc., que constituyen sistemas demográficos muy complejos con su propia originalidad. Las teorías de la población desarrolladas durante el último siglo se refieren precisamente a esos grandes aglomerados. Los teóricos de la población, suelen prestar atención a las cifras, pero ignoran la articulación de la población en sistemas propios e incluso el sistema territorial del que la población forma parte. Para el demógrafo la escala es, probablemente, algo accesorio. En cambio, en el análisis sociocultural la escala es algo fundamental. El funcionamiento de los macrosistemas y microsistemas demográficos es semejante, pero el papel de las variables y el nivel de interconexiones con otros sistemas y subsistemas son diferentes en cada tipo de sistema. Los modos de hacer; es decir, la cultura de los pequeños y grandes grupos humanos, aunque persigan los mismos fines, siguen caminos diferentes. Las actitudes y comportamientos socioculturales de la población, en las grandes concentraciones urbanas, por ejemplo, no son generalizables a las pequeñas aldeas. Cada porción de espacio soporta un sistema demográfico 
propio. Las sociedades rurales difieren profundamente de las sociedades urbanas. Incluso en una misma concentración urbana la estructura sociocultural de los barrios presenta notables diferencias de unos barrios a otros.

El conjunto de la población mundial constituye un sistema cerrado, aunque dividido en multitud de ámbitos territoriales que soportan sistemas demográficos locales. El centro de interés de las teorías de la población y de las políticas demográficas patrocinadas por los organismos internacionales es el macrosistema mundial y apenas reparan en los sistemas demográficos locales. Sin embargo, la base demográfica de los sistemas socioculturales la constituyen, precisamente, los sistemas demográficos locales y microsistemas de cuya estabilidad dependen habitualmente las condiciones de vida de la población.

Los sistemas demográficos son reales, abiertos y dinámicos. Por su propia naturaleza están en constante proceso de cambio, ya que la duración y eficacia de los elementos que los componen son limitadas. De ahí que estos sistemas tiendan a la inestabilidad y sean muy sensibles a los cambios de los otros sistemas y subsistemas con los que interactúan. Si estos sistemas y subsistemas permanecen estacionados, el sistema demográfico lo hace también. Por el contrario, si otros sistemas asociados al sistema territorial en el que conviven aumentan su eficacia, el sistema demográfico deberá modificar su composición y estructura para adaptarse también a las nuevas circunstancias. La estabilidad de un sistema demográfico guarda relación con la estructura de la población por edad, sex-ratio, población activa y dependiente, nivel de formación, etc. lo cual solo se consigue con un determinado tipo de población estable.

Cada sociedad y cada momento histórico se caracterizan por una determinada estructura de población estable, cuya cuantía varía en cada caso particular. Los sistemas demográficos que se han dado en las diferentes partes del mundo han sido sistemas equilibrados o, mejor, sistemas estables, con multitud de variedades.

Por lo que se sabe de la evolución de la población mundial, la ruptura del equilibrio demográfico y, por lo tanto, de la estabilidad de los respectivos sistemas, la han producido siempre las revoluciones demográficas impulsadas por importantes cambios económicos, sociales y culturales. Para subsistir a estos cambios, los sistemas demográficos han tenido que mantener la estabilidad y acomodarse a las circunstancias socioculturales de cada momento.

La estabilidad de los sistemas demográficos depende de que mantengan su eficacia en el conjunto de los sistemas que comprende el sistema sociocultural. Es lo que sucedió, durante la transición del siglo XviII. Los actuales sistemas demográficos que salieron de aquella transición y han servido para elaborar las teorías de la población, están perdiendo rápidamente eficacia en 
las regiones donde primeramente se implantaron y han perdido estabilidad debido, sin duda, a los profundos cambios socioculturales que ha sufrido el mundo en los últimos doscientos cincuenta años. Actualmente, los países de cultura occidental están iniciando una nueva transición demográfica caracterizada, como las anteriores, por la ruptura de la estabilidad demográfica. El carácter más perceptible de la nueva transición es el envejecimiento de la población y desconocemos el modelo de estabilidad demográfica hacia el que nos encaminamos.

La inestabilidad de los sistemas demográficos se manifiesta en primer lugar por la percepción de que hay un exceso de población o por el contrario un subpoblamiento. Cuando se dan estas circunstancias, la sociedad busca el óptimo de poblamiento que, por su propia naturaleza es imposible de definir con precisión. Algunos macrosistemas se revelan inestables por el envejecimiento progresivo de la población y la caída de la fecundidad, que disminuyen la capacidad del capital humano disponible, e intentan resolver el problema mediante la inmigración, como sucede en Europa, cuyo crecimiento natural es tan bajo que no alcanza la tasa de reemplazamiento generacional. En otros, en cambio, la inestabilidad proviene de la incapacidad de dicho capital para asegurar y mejorar las condiciones de vida de la población e incluso de satisfacer las necesidades primarias, como sucede en los países menos desarrollados. La mayoría de los microsistemas son inestables como consecuencia del envejecimiento de la población y la emigración. Cuando en un sistema demográfico coinciden la insuficiencia de efectivos y la inoperancia de éstos para mantener y desarrollar el sistema es posible hablar de inestabilidad demográfica que se concreta en lo que denominamos déficit demográfico.

Como se ha dicho anteriormente, la primera revolución demográfica debió ser la del Neolítico. La segunda revolución conocida y estudiada tuvo lugar en Europa en el siglo XVIII. Entre ambas revoluciones, las culturas occidentales han consumido unos 10.000 años, pero ha debido de haber otras muchas revoluciones demográficas, aunque haya sido a escala local y regional, como la que afectó a los pueblos amerindios después del descubrimiento. Actualmente hay pueblos que hace poco más de un siglo que han salido de su Neolítico sin haber desarrollado por completo la primera transición. Aunque los organismos internacionales les impulsan a llevar a cabo determinadas políticas demográficas, estos pueblos encuentran muchas dificultades para llevar a cabo una auténtica revolución demográfica semejante a la del siglo xviII. Sus sistemas demográficos son inestables por la excesiva proporción de población joven. En cambio, en los países más desarrollados la inestabilidad proviene del envejecimiento relativo de la población. 
A escala mundial actualmente rigen dos sistemas demográficos diferentes. Uno, que afecta a los pueblos y culturas menos desarrolladas, caracterizado por la elevada proporción de población joven y rápido crecimiento demográfico; y otro que actúa en los países más desarrollados, cuyas características demográficas son el envejecimiento de la población y el crecimiento cero.

Los sistemas demográficos son muy sensibles al volumen y características de la población, ya que ésta constituye el input intermedio, junto a otros inputs materiales o inmateriales, que hacen posible el funcionamiento del sistema sociocultural y garantizan la satisfacción de las necesidades del grupo. La eficacia de un sistema demográfico depende, entre otras cosas, del nivel sociocultural alcanzado por sus miembros. Cuando la eficacia de un sistema demográfico disminuye, el sistema entra en una fase de degradación que concluye en la manifestación explícita del déficit.

A macroescala, mientras los países más desarrollados son actualmente muy sensibles al déficit cuantitativo, en los países memos desarrollados preocupa el déficit cualitativo por el alto porcentaje de población que carece de instrucción. Los sistemas socioeconómicos y culturales de estos países se manifiestan incapaces de satisfacer las necesidades de educación y formación de una población mayoritariamente joven que se duplica cada pocos años. Los países más desarrollados, por el contrario, con un crecimiento natural estancado o ligeramente superior a cero registran un déficit cuantitativo que intentan compensar con la inmigración.

\section{DÉFICIT DEMOGRÁFICO Y DESVERTEBRACIÓN DEL TERRITORIO}

El concepto de déficit demográfico guarda una estrecha relación con la social carrying capacity que en la Nueva Enciclopedia de la Población, editada en 2003 por Paul Demeny y Geoffrey McNicoll, Jai Ranganathan y Gretchen C. Daily, se define como «el máximo volumen de población que un determinado sistema social y las pautas de consumo inherentes al mismo pueden sostener». A escala local, puede darse el caso de que, siendo el medio natural potencialmente capaz de producir recursos suficientes para sostener un determinado volumen de población, falte capacidad social para poner en acto el potencial existente o para poner en funcionamiento sistemas de organización que hagan posible la satisfacción de las necesidades. La social carrying capacity puede disminuir por multitud de causas, pero la experiencia muestra que la ineficacia del sistema productivo va generalmente unida a la degradación del sistema demográfico por envejecimiento de la población, si no hay renovación generacional. 
Con el tiempo, todos los sistemas demográficos pierden eficacia, lo cual hace que se degraden paulatinamente, sobre todo si no se adaptan a las características del sistema territorial al que pertenecen. La desvertebración del territorio va siempre precedida de la desvertebración demográfica. En los sistemas demográficos locales, el envejecimiento y sobreenvejecimiento de la población conducen inexorablemente a la desvertebración del territorio por ineficacia del sistema demográfico, incapaz, en tales circunstancias de desarrollar las funciones que normalmente se le atribuyen en un sistema territorial.

La población vive y se organiza de acuerdo con su manera peculiar de percibir el territorio, lo cual constituye, de hecho, una manifestación cultural. Se establece así un sistema de relaciones entre la población y el territorio, de manera que éste se convierte en marco de vida o espacio de vida de aquella. El resultado de todo ello son situaciones de equilibrio entre la población y el territorio en el que habita. El déficit demográfico, no es otra cosa que la ruptura del equilibrio del sistema demográfico propio y la pérdida de sensibilidad para percibir el territorio como espacio de vida. El envejecimiento y la emigración, cuando son excesivos propician el estancamiento del sistema productivo y el abandono de amplísimas extensiones de los ecótopos agrarios, con la consiguiente degradación del bienestar social, por el incremento de la dependencia, y del medio ambiente, por falta de mantenimiento.

Restringiendo nuestras reflexiones a la población, entendida como capital humano, podemos concluir que la desintegración del territorio como espacio de vida de una comunidad comienza cuando el capital humano, que constituye lo esencial del sistema demográfico es insuficiente o inadecuado para alcanzar los outputs que garantizan un determinado nivel de vida.

Si se mantiene la tendencia actual de alargamiento de la vida, la población de los estratos superiores de la pirámide de edades será mayoritaria a mediados de la actual centuria. Las condiciones de vida de la población habrán cambiado, sin duda y se generalizará la propuesta de Lázaro (2007) de dar vida a los años. Es lo mismo que proponen los expertos en envejecimiento Rowe y Kahn (1997).

Fecha de recepción: 12/09/2012

Fecha de aceptación: 16/10/2012 


\section{BIBLIOGRAFÍA}

Brentano, L. J. (1910): "The Doctrine of Malthus and the Increase of Population During the Last Decades". Economic Journal, 20/79, pp. 371-93.

Casas Torres, J. M. (1982): Población, desarrollo y calidad de vida. Madrid, Rialp, $491 \mathrm{pp}$.

Coale, A. J. y Hoover, E. M. (1958): Population Growth and Economic Development in Low Income Countries. Princeton, Nueva Jersey, Princeton University Press, 389 pp.

Coontz, Sidney H. (1957): Teorías de la población y su interpretación económica. México, Fondo de Cultura Económica, 200 pp.

Castro, J. de (1961). Geografía del hambre. Santiago de Chile, Editorial universitaria, $240 \mathrm{pp}$.

Demangeon, A. (1942): Problèmes de Géographie Humaine. Paris, Armand Colin, 408 pp.

Demeny, P. et al. (2003): Encyclopedia of Population. Washington, MacMillan, Revised Edition.

Derruau, M. (1961): Prècis de Gèographie Humaine. Paris, Librairie Armand Colin, 575 pp.

Doubleday (1841): The true law of population shewn to be connected with the Food of the People. London, Routledge, 203 pp.

Dumont, A. (1890): Depopulation et civilisation. Étude démographique. Paris, Lecrosnier et Babé, 532 pp.

Ehrlich, P. y Ehrlich, A. (1970-1972): Population, Resources, Environment. Issues in Human Ecology. San Francisco, W. H. Freeman and Co, 523 pp.

George, P. (1951): Introduction a l Étude Géographique de la Population du Monde. Travaux et Documents, Cahier 14, Paris, I.N.E.D.-P.U.F., 284 pp.

Higueras Arnal, A. (1992): La población mundial hacia el Tercer Milenio. Zaragoza, Universidad de Zaragoza, 34 pp.

Johnston, R. J. et al. (eds.) (1988): Dictionary of Human Geography. Oxford, Blackwell Publishers.

Keynes, J. M. (1970): Primer ensayo sobre la población: Robert Malthus (1766-1834). Madrid, Alianza Editoral, 318 pp.

Landry, A. (1934): La revolution démographique. Paris, Sirey, 127 pp.

Le Lannou, M. (1949): La Géographie Humaine. Paris, Flammarion éditeur, 254 pp.

Noin, D. (1997): "L' Humanité sur la planète. Carte mondiale E.: 1/15.000.000", en UNESCO (ed.): Atlas et cartes scientifiques. Paris, Èditions UNESCO, 46 pp.

Organización Mundial de la Salud (2012): Informe 2012 OMS/UNICEF: progresos sobre el agua potable y saneamiento. Estadisticas sanitarias mundiales 2011. OMT, 178 pp.

Population Reference Bureau (2012): World Population Data Sheet. Washington. Disponible en: www.prb.org (Fecha de consulta: 15/08/2012).

Ratzel, F. (1891): Antropogeografía. Stuttgart, 606 pp.

Rowe, J. W. y Kahn, I. R. (1997): "Successful Aging”. The Gerontologist, 37/4, pp. 433-440. 
Sauvy, A. (1954): Theorie génerale de la population. Paris, PUF, 2 vols.

Sorre, M. (1943-1952): Les fondaments de la géographie humaine. Paris, Armand Colin, 3 vols. $(440,1031,440)$.

Thompson, W. S. (1929): "Population". American Sociological Review, 34/6, pp. 959-975.

Vallois, H. V. (1952): Les hommes fossiles. Eléments de paléontologie humaine. Paris, Masson, $492 \mathrm{pp}$.

Verhulst, P. Fr. (1838): Notice sur le loi que la population porsuit dans son acroissement. Bruselas, Corresp. Maths. Phis., 10, pp. 113-121.

Vidal de la Blache, P. (1955): Principes de Géograhie Humaine. Reimpresión de la edición póstuma publicada en 1921. Paris, Librairie Armand Colin, 327 pp.

\section{RESUMEN}

En Geografía Social y Cultural, entendida como «estudio de las relaciones entre el hombre y el medio» y como «ciencia del hombre habitante», los sistemas demográficos constituyen el fundamento de los sistemas socioculturales.

Los sistemas demográficos se construyen a expensas de la población que en cada momento vive en las diferentes porciones de la superficie terrestre, muy irregularmente repartida sobre el planeta, y cuyos componentes conviven y se agrupan para satisfacer sus necesidades. El conjunto de la Humanidad se presenta diferenciado por el número de individuos que los integran, por las características de éstos y por la dinámica de los procesos de crecimiento interno, lo que permite diferenciar los sistemas demográficos por una escala de magnitudes en relación con el número de individuos que contienen, la naturaleza de las necesidades que deben satisfacer y su ámbito territorial de acción. La eficacia y estabilidad de los mismos depende, entre otras cosas, del nivel sociocultural alcanzado por sus miembros. Cuando la eficacia de un sistema demográfico disminuye, el sistema entra en una fase de degradación que concluye en la manifestación explícita del déficit.

La base demográfica de los sistemas socioculturales la constituyen los microsistemas de cuya estabilidad dependen habitualmente las condiciones de vida de la población.

PAlabras Clave: Sociocultural; Sistema demográfico; Transición demográfica; Maltusianismo; Social carrying capacity; Déficit demográfico.

\section{Abstract}

In Social and Cultural Geography, understood as the «study of the relationship between humans and their environment» and as «science of human settlers», demographic systems are the foundation of sociocultural systems.

Demographic systems are built at the expense of the population that lives, so unevenly spread out, on the surface of the earth at any given time and whose components live together and group in order to satisfy their needs. Humanity as a whole is differentiated by the number of individuals that make up the different groups, their characteristics and the dynamics of the processes of internal growth. These factors allow 
one to differentiate the different demographic systems using a scale of magnitudes in relation to the number of individuals they contain, the nature of their needs and their territorial sphere of influence. Among other things, their effectiveness and stability depend on the sociocultural level of the members of the group. When the effectiveness of a demographic system diminishes, it enters a stage of degradation which concludes in the explicit manifestation of the deficit. The demographic foundation of sociocultural systems is made up of microsystems whose stability usually depends on the living conditions of the population.

KEY WORDS: Sociocultural; Demographic system; Demographic transition; Malthusianism; Social carrying capacity; Demographic deficit.

\section{RÉSUMÉ}

Dans la Géographie sociale et culturelle, entendue comme «l'étude des relations entre l'homme et le milieu» et comme «la science de l'homme habitant», les systèmes démographiques représentent le fondement des systèmes socioculturels.

Les systèmes démographiques sont construits aux dépens de la population qui habite à chaque période les différentes parties de la surface terrestre, distribuée de façon très irrégulière sur la planète, et dont les composants cohabitent et se groupent pour donner satisfaction à leurs besoins. L'humanité dans son ensemble se présente différenciée par le nombre d'individus qui l'intègrent, par leurs caractéristiques et par la dynamique des processus de croissance interne, ce qui permet de différencier les systèmes démographiques à travers une échelle de magnitudes par rapport au nombre d'individus qu'ils contiennent, la nature des besoins qu'ils doivent satisfaire et leur portée d'action territoriale. Leur efficacité et stabilité dépend, entre autres éléments, du niveau socioculturel atteint par leurs membres. Si l'efficacité d'un système diminue, le système entre dans une phase de dégradation qui se termine par la manifestation explicite du déficit.

La base démographique des systèmes socioculturels est constituée par des microsystèmes, et les conditions de vie de la population dépendent normalement de leur stabilité.

MotS ClÉS: Socioculturel; Système démographique; Transition démographique; Malthusianisme; Social carrying capacity; Déficit démographique. 